\title{
Semi-Markov reliability model of functioning of wireless telecommunication system with complex control system
}

\author{
Bobalo Yu. Ya., Horbatyi I. V., Kiselychnyk M. D., Medynsky I. P., Melen M. V. \\ Lviv Polytechnic National University, \\ 12 S. Bandera Str., 79013, Lviv, Ukraine
}

(Received 10 September 2019; Revised 25 October 2019; Accepted 28 October 2019)

\begin{abstract}
A mathematical reliability model in the form of a semi-Markov process of failures and recoveries has been constructed for a high-reliability wireless telecommunication system with a complex control system. The main characteristics of this process have been obtained, as well as an analytical expression for estimation of the probability of retaining the system in an operable state. This expression depends on the parameters of the semiMarkov process, which are determined by the reliability characteristics of the controlled modules, of their control hardware and by the parameters of the used means of control of the correct functioning of the system under consideration.
\end{abstract}

Keywords: high reliability system, complex control system, semi-Markov process, Markov recovery equation, wireless communication system.

2000 MSC: $60 \mathrm{~J} 20,60 \mathrm{~K} 15,60 \mathrm{~K} 20$

UDC: 621.39

DOI: $10.23939 / \mathrm{mmc} 2019.02 .192$

\section{Introduction}

Wireless communication systems refer to a class of systems that operate on a real-time scale, which imposes certain restrictions on their design, and, at the same time, gives rise to a number of problems, one of which is to ensure high reliability of their functioning over a long time. This fact causes the urgent need to construct such systems using the redundancy and a developed complex control system (CCS) for their proper functioning [1, p. 51], which allows for the self-recovery of such systems. It should be noted that along with measures to introduce the backup and recovery of having failed hardware, the correcting imperfect programs or data, the control is one of the effective means of improving the reliability and dependability of telecommunication systems. The main means for detecting failures in the systems of this class are the means of hardware (operational) control [2, p. 211], the implementation of which requires the introduction of additional equipment. However, for some reasons (significant hardware costs to ensure high efficiency of operational control, significant difficulties in the operational control of individual modules of the system, etc.), it is rarely possible to cover the hardware control of the system as a whole. Therefore, the control of the correct functioning of high-reliability systems is carried out by CCS. When using CCS, the control of the correct functioning of the system is organized on the basis of periodic software (test) control, which controls the performance of the system modules and their control hardware, and which is used along with the hardware control, which allows establishing with certain certainty the true state of the system in the period between software control. Accordingly, at the stage of system designing of high-reliability telecommunication systems of wireless communication, before developers there arises a problem of estimation of expediency of application of certain methods of control of the correct functioning of the system being designed, and substantiation of requirements for their characteristics, based on providing the required level of reliability of the controlled system functioning.

It should be noted that at present there are relatively few works on the reliability of complex technical systems using CCS, which telecommunication systems refer to. Moreover, the known works present reliability models of controlled objects, each of which is suitable for certain assumptions and 
restrictions that are not implementable in practice. For example, in [2, pp. 218, 252] and [3], the reliability models of the processor do not take into account the failures of the hardware and software of the controlled object and its control means; it has also been made a number of assumptions that are not implemented in practice, such as failure and recovery flows are taken to be exponential, and in [4, pp. 86, 97], [5, pp. 158, 159] the formation of reliability models of complex systems is made based on the assumption that the control is continuous and reliable, i.e., ideal. The indicated above drawbacks of these works significantly affect the reliability of research results.

The purpose of this work is to develop a semi-Markov reliability model of functioning of a wireless telecommunication system with a complex control system, which at the stage of system design will allow proper evaluating the influence of different control methods on the reliability of the system being projected.

\section{Assumptions and notation}

We assume that the modules that make up the wireless telecommunication system operate (fail, being controlled, recover, etc.) independently of each other, and the given reliability of each of them can be achieved by different methods. The expression for the total indicator of the reliability of this wireless telecommunication system can be written [6, p. 49] in the form

$$
R(t)=\prod_{i=1}^{n} R_{i}(t),
$$

where $R_{i}(t)$ is the reliability index of the $i$-th module of the wireless telecommunication system, $n$ is the number of modules of the system. According to the formula (1), it is expedient to solve the formulated problem with respect to an arbitrary controlled module of this system. Also in this article we consider the separate redundancy of the controlled module and of the control hardware of its correct functioning.

In the wireless telecommunication system, which consists of the basic and backup typical elements of replacement (devices, modules, etc.), there are various disturbances of the process of its functioning, which are caused by both permanent failures and short-term faults that are self-eliminating (faults). The flows of failures and faults are independent, and the time before they occur are random variables, distributed according to the law $F(t)=P\{\xi \leqslant t\}$ with the corresponding parameters $\lambda_{\mathrm{fm}}, \lambda_{\mathrm{fch}}, \lambda_{\mathrm{flm}}$ and $\lambda_{\text {ffch }}$ (intensities of failures of the module and control hardware, and of faults of the module and control hardware respectively).

The state of this system is controlled continuously by hardware and periodically by control software. Let us denote $p_{\mathrm{dfh}}, p_{\mathrm{dfh}} \in(0,1)$ and $p_{\mathrm{dflh}}, p_{\mathrm{dflh}} \in(0,1)$ to be the probability of detection of failures and faults of the hardware control, respectively. Since the control hardware provides instant detection of failures and faults, the average time $t_{\mathrm{fdch}}$ of failures detection by means of hardware is zero.

However, the control hardware, like other technical devices, has the failures and faults proneness, resulting in errors of the first and second kind [2, p. 218], [7, p. 83], [8, p. 194]. The error of the first kind is characterized by the conditional probability $\alpha_{\mathrm{ffch}}, \alpha_{\mathrm{ffch}} \in(0,1)$ of the false failures and by its intensity $\lambda_{\mathrm{e} c h \alpha}$, and the error of the second kind is characterized by the conditional probability $\beta_{\mathrm{fthch}}$, $\beta_{\mathrm{fthch}} \in(0,1)$ of the failure throughput and by its intensity $\lambda_{\mathrm{ech} \beta}$.

Software (test) control of the correct functioning of the controlled system and of its control hardware is carried out over random time intervals $\zeta$, distributed according to the law $G(t)=P\{\zeta \leqslant t\}$. Suppose that the duration $t_{\mathrm{sc}}=\varsigma$ of software control is also a random variable, distributed according to the law $H(t)=P\{\varsigma \leqslant t\}$. Due to the imperfection of control software (it is not ensured full coverage of the examination of the elements of the controlled object) [2, p. 198], the hardware failures of this system are detected with the probability $p_{\text {pfds }}, p_{\text {pfds }} \in(0,1)$, where $p_{\text {pfds }}$ is the probability of detection of failures by software means of control. As compared to the hardware control, the software control is more reliable. During the software control of the correct functioning of this system, the faults of 
the controlled equipment can occur, and they lead to errors of the first kind, which are characterized by the conditional probability $\alpha_{\mathrm{ffs}}, \alpha_{\mathrm{ffs}} \in(0,1)$ of the false failures and by its intensity $\lambda_{\mathrm{es} \alpha}$. At the same time, an assumption is made for impossibility both of hardware and software controls faults that lead to neglecting the failures (improbable errors of the second kind). In all cases of detection of failures, their identification is carried out, and when the fact of the presence of a failure is established, an unscheduled program control is carried out with the purpose of localization of the failure and the recovery of the system operation is done by replacement of the failed module with redundant one. The time $t_{\mathrm{rhm}}=\chi$ of recovery of the hardware of the controlled module is a random variable distributed according to the law $K(t)=P\{\chi \leqslant t\}$. After the restoration of efficiency of this system, redesign of the moment of carrying out the following software control of its correct functioning is done.

Wireless communication hardware control can be either embedded or acts as separate functional modules (e.g., control redundancy). In this regard, when the control hardware failures are detected, depending on the method of redundancy, only the failed control hardware or the entire module are to be recovered. The time $t_{\text {rch }}=\eta$ of recovery of the control hardware is also a random variable distributed by the law $L(t)=P\{\eta \leqslant t\}$.

The final decision on the presence of failure of a particular module of a wireless communication system or its control hardware can be made based on the results of software control, i.e., the decision on the need to recovery of the functionality of this module can be made only as a result of software control. In this regard, the time between the start of recovery of a controlled system is a discrete random variable, the sequence of which forms a simple discrete recovery process. It is obvious that the use of CCS in a wireless communication system leads to the extension of the set of its phase states [6, p. 50]. The states of problems detected and missed by the control means emerge as well as the software control execution, module recovery, etc., into which the controlled module transits in the course of its functioning. In this regard, the functioning of this module over time is described by a discrete random process whose states correspond to its physical states. We denote the states of the controlled module by the letter $\mathrm{S}$ with an index.

We define the set $\mathbb{E}$ of the states of a random process as follows: $S_{0}$ corresponds to the functioning of the module in the absence of failures (failures and faults); $S_{1}$ corresponds to the functioning of the module in the presence of an error caused by faults having been missed by control hardware; $S_{2}$ corresponds to the state of the module which is characterized by the detection of module failure by control hardware; $S_{3}$ corresponds to the functioning of the module according to the program of failure identification detected by control hardware; $S_{4}$ corresponds to the functioning of the module with missed failure by control hardware; $S_{5}$ corresponds to the occurrence of a failure of control hardware, in the result of which they fix the false failure of the controlled module; $S_{6}$ corresponds to the failure of control hardware, in the result of which all subsequent failures of the controlled module will be missed; $S_{7}$ corresponds to the termination of the functioning of the operable module according to the main program and its transition to the regime of scheduled program control; $S_{8}$ corresponds to the transition of the module with the failure missed by hardware control to the scheduled program control regime; $S_{9}$ corresponds to the functioning of the module according to the program of identification of a failure caused by a signal of a false failure; $S_{10}$ corresponds to the transition of the module, in which the control hardware failed, to the scheduled program control regime; $S_{11}$ corresponds to the functioning of the module with the failure having been missed by hardware and software control; $S_{12}$ corresponds to the transition of the module with the failure having been missed by hardware and software control in the scheduled program control regime; $S_{13}$ corresponds to the emergence in the module with the failure having been missed by hardware and software control of a new failure detected by control hardware; $S_{14}$ corresponds to the emergence of a new failure in the module with the failure having been missed by hardware and software means of control, which results in the fixing of the failure of this module; $S_{15}$ corresponds to the transition of the module with the failure having been missed by hardware and software control to the mode of identification of the failure due to the detection by hardware control of a new failure of the controlled module; $S_{16}$ corresponds to the transition of the module with the failure detected by hardware control to the regime of unscheduled program control; $S_{17}$ corresponds to the

Mathematical Modeling and Computing, Vol. 6, No. 2, pp. 192-210 (2019) 
transition of the module with the failure having been missed by hardware and software control to the regime of identification of the failure caused by the failure of control hardware, which results in fixing the failure of this module; $S_{18}$ corresponds to the emergence in the module with the failure having been missed by hardware and software control of a new failure of control hardware, in the result of which all subsequent failures of this module will be missed by it; $S_{19}$ corresponds to the transition of the module with the failure having been missed by hardware and software control to the unscheduled program control due to the detection a new failure of this module made by control hardware; $S_{20}$ corresponds to the transition of the module with the failure having been missed by hardware and software control to the unscheduled program control due to the failure of its control hardware, which results in the fixing of the failure of this module (false failure); $S_{21}$ corresponds to the transition of the module the failure having been missed by hardware and software control, as well as with the subsequent failure of its control hardware, to the regime of scheduled program control; $S_{22}$ corresponds to the restoration of performance of the controlled module; $S_{23}$ corresponds to the recovery of the control hardware of this module.

Let us now proceed to establishing the direction of the transitions of a random process between the specified states, as well as the peculiarities of these states.

If the random process is in the state $S_{0}\left(S_{11}\right)$, after some random time $\xi$, it will transit to one of the states $S_{1}, S_{2}, S_{4} \div S_{7}\left(S_{12} \div S_{14}, S_{18}\right)$ which correspond to the states of the controlled module, which are caused by its faults emergence or by the approach of a moment of the scheduled program control of its correct functioning. Since these events are random and the probabilities of occurrence of different intervals between failures (between hardware faults and failures) and of the duration of the program control period are distributed according to an arbitrary law, the average duration of the random process in the states $S_{0}$ and $S_{11}$ is random with an arbitrary distribution function. Moreover, the specified time does not depend on the previous evolution of the process but depends only on these states.

Since the controlled module is in the state $S_{1}$ until the moment of completion of its tasks, the duration of which is much shorter than the time before the following failure of the module or its control hardware, the random process that describes the behavior of this module in time can only go to the state $S_{0}^{\prime}$. Thus, the average duration of a random process in the state $S_{1}$ depends only on this state and does not depend on its previous evolution.

The states of the random process $S_{2}, S_{13}$ and $S_{5}, S_{14}$ correspond to the detection of failures of the controlled module and its control hardware, respectively. Therefore, in accordance with the peculiarities of functioning of this module, the random process from the states $S_{2}, S_{5}, S_{13}$, and $S_{14}$ can transit only to the states $S_{3}, S_{9}, S_{15}$, and $S_{17}$, respectively. The average duration of the random process in the states $S_{2}, S_{5}, S_{13}$, and $S_{14}$ correspond to the average time of failure detection by means of control hardware, which depends on the method of organization of processing of control information (e.g., the time of processing breaks). Therefore, the average duration of the random process in the mentioned states depends only on these states and does not depend on the previous evolution of this process.

The states of the random process $S_{3}, S_{9}, S_{15}$, and $S_{17}$ correspond to the identification of the detected failure, i.e., to the repetition of the corresponding fragment of the program during the implementation of which this failure has been detected. In accordance with the peculiarities of the functioning of this module, the random process can transit from the states $S_{3}, S_{15}, S_{17}$ to the states $S_{16}, S_{19}, S_{20}$, respectively; from the state $S_{9}$ it can transit to the state $S_{23}$. In addition, the random process can also transit back from the states $S_{15}$ and $S_{17}$ to the state $S_{11}$ (if fault is in this module), from the state $S_{3}$ to state $S_{0}^{\prime}$, and from state $S_{9}$ to the operable state of the module (denoted by $S_{0}^{\prime \prime}$ ), which differs from the states $S_{0}$ and $S_{0}^{\prime}$ by the residual time before the transition of the random process to the state $S_{7}$. From the aforesaid, it follows that the average duration of a random process in the states $S_{3}, S_{9}, S_{15}$, and $S_{17}$ depends only on these states and does not depend on the previous evolution of this process.

Since the states of the random process $S_{4}, S_{6}$, and $S_{18}$ correspond to the functioning of the controlled module with a missed failure, and the time before the new failure of this module is much longer than 
the average time before the following moment of scheduled program control of the correct functioning of the module, then the random process can transit from the specified states only to the states $S_{8}, S_{10}$, and $S_{21}$, respectively. Thus, the moments in which the random process occurs in the states $S_{4}, S_{6}$, and $S_{18}$ are random, and the output from them occurs in random time with an arbitrary distribution function. Therefore, the average duration of a random process in these states is determined both by the moment of its entering into these states and the moment of exit out of them.

The states of the random process $S_{7}, S_{8}, S_{10}, S_{12}$, and $S_{21}$ correspond to the scheduled program control of this module, and the states $S_{16}, S_{19}$, and $S_{20}$ correspond to the unscheduled program control. In this regard, the random process from the states $S_{7}$ and $S_{12}$ can only transit to the states $S_{0}$ and $S_{11}$, respectively (since the time before failure of the module or its control hardware is much longer than the program control duration), from the states $S_{10}, S_{20}$, and $S_{21}$ it can transit only to the state $S_{23}$ (since all failures of control hardware are detected by software controls - by control test), from the states $S_{16}$ and $S_{19}$ to the state $S_{22}$, and from the state $S_{8}$ to either state $S_{11}$ or state $S_{22}$.

The average duration of the random process in the states $S_{7}, S_{8}, S_{10}, S_{16}, S_{19} \div S_{21}$ corresponds to the duration of software control of this module and, therefore, does not depend on the previous evolution of this process, but depends only on these states.

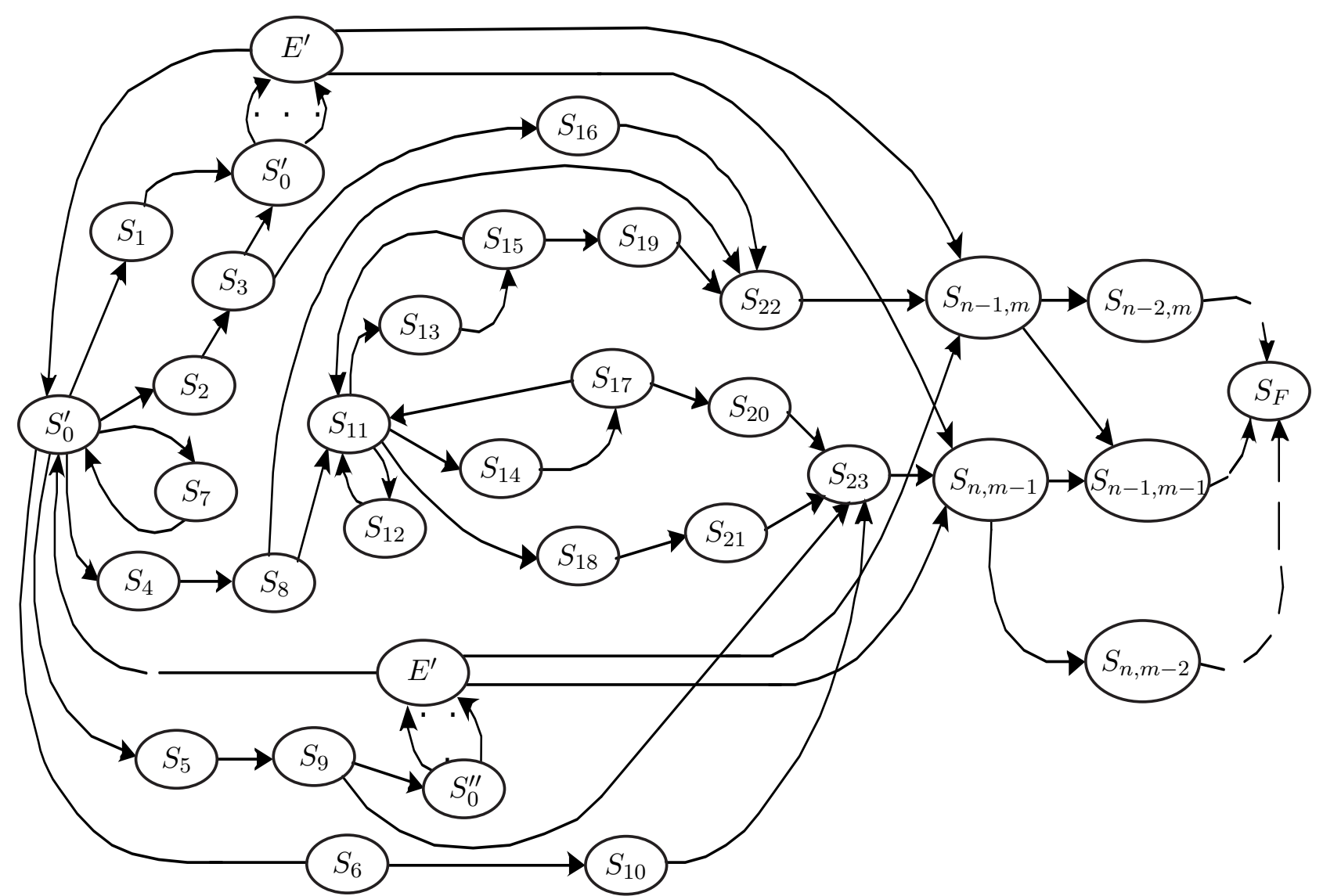

Fig. 1. Graph of states and transitions of arbitrary controlled module of wireless communication system with CCS.

The states of the random process $S_{22}$ and $S_{23}$ correspond to the restoration of the operability of the controlled module and its control hardware, respectively. In this regard, after some random time $t_{\mathrm{rhm}}$, this process will transit from the specified states to the states (we denote them by $S_{m, n}$ ), which correspond to the operable states of the module, but differ from the state $S_{0}$ by the number of serviceable reserve modules $m$ and the control hardware $n$, respectively.

The average duration of the random process in the states $S_{22}$ and $S_{23}$ also depends only on these states and does not depend on its previous evolution. 
Further, the phase space of the states of the random process begins to expand from the states $S_{0}^{\prime}$ and $S_{n, m}$, resulting in new sets of states $E^{\prime}$ and $E_{m, n}$, which are constructed similarly to the aforesaid set of states $E$. Note that in random time $\xi$, the random process of the set $E^{\prime}$ of states will transit either to the state $S_{0}$ (unless the failure of the controlled module or its control hardware occurs by the end of the scheduled program control) or to the state $S_{n, m}$ (in other case).

The phase space of the random process states will expand until it reaches the state $S_{F}$, which corresponds to the complete failure of the controlled module.

The directed graph of states $G(E, U)$, whose set of vertices will be equated with the set of states of the random process, and the direction of transitions from state to state will be equated with its arcs, for an arbitrary controlled module of the wireless communication system corresponding to the model is shown in Fig. 1 (state sets $E^{\prime}$ and $E_{m . n}$ are shown in simplified form).

\section{The system mathematical model construction}

The obtained phase space of states has a large dimension and is of little use for reliable system analysis. The most radical approach to overcome the complexity of the analysis of the obtained model is to construct a simpler, larger model, the analysis of which is much easier than the analysis of the real one [9, p. 129], [5, p. 10], which we will use later.

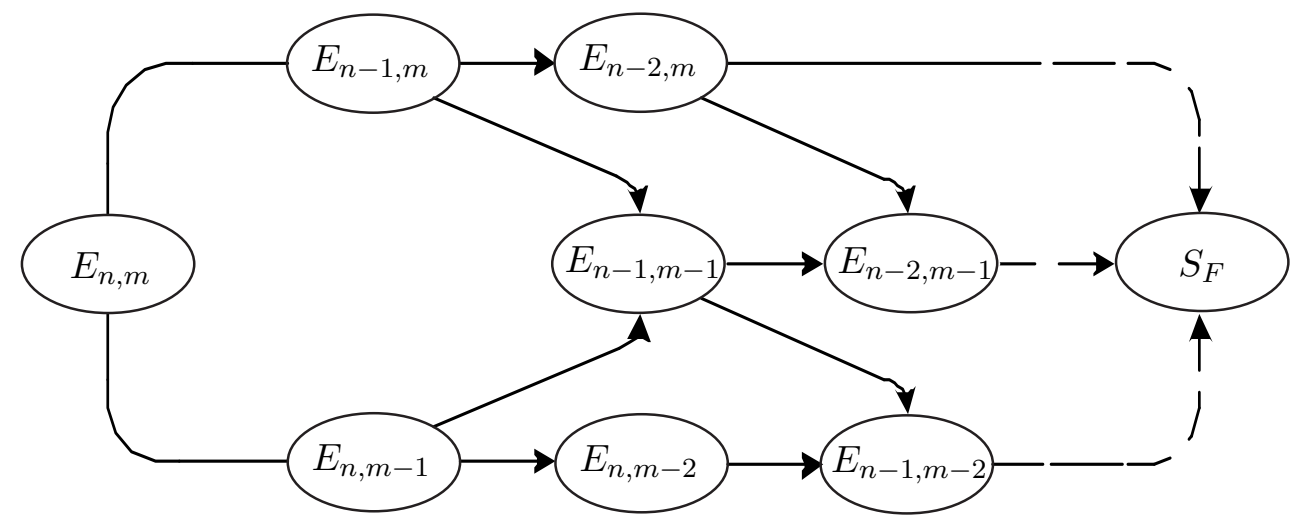

Fig. 2. Extended graph of states and transitions of arbitrary controlled module of wireless communication system with CCS.

From the above-mentioned analysis of the states of a random process and from the direction of the transitions from state to state, it is easy to see that transitions between indicated states are carried out with different intensity. For example, transitions between the sets of states $E$ and $E_{m, n}$ occur much less frequently than transitions within them. This statement is correct because the transitions of a random process between the specified sets of states correspond to the transitions caused by failures of the controlled module or its control hardware, and transitions within these sets correspond to the transitions caused by faults and scheduled test control. It is known that the failure rate of the equipment is much less than the intensity of its faults, and the time before the failure of the controlled module is much longer than the time interval between subsequent moments of scheduled program control of its correct functioning. Using the specified peculiarity of transitions of the random process, the whole set of its states can be subdivided into subsets so that the frequency of transitions between the states of each of them significantly exceeds the frequency of transitions between them. As a result of this division, we obtain $h$ continuous subsets of states, each of which can be aggregated into a separate state. Thus, as a result of these procedures, we obtain an aggregated graph of the states of the random process, which is shown in Fig. 2.

To analyze the obtained model, we use methods known from the theory of phase extension of states [9, p.131], [10, pp. 40,54], [11, p. 73]. In this case, the study of this model is reduced to the 
investigation of a random process of transitions between the aggregated states and its durations in these states. Based on [8:199], the expression to determine the indicator $R_{i}(t)$ of reliability of an arbitrary controlled module of the wireless communication system is written in the form

$$
R_{i}(t)=P\left\{S(t) \in \mathbb{E}_{R}\right\} P\left\{S(t) \in \mathbb{E}_{0}\right\}
$$

where $P\left\{S(t) \in \mathbb{E}_{R}\right\}$ and $P\left\{S(t) \in \mathbb{E}_{0}\right\}$ are the probabilities of presence of the random process at the moment $t$ in the subset $\mathbb{E}_{R}$ and $\mathbb{E}_{0}$ of states, respectively. The subset $\mathbb{E}_{R}$ of the states of the random process corresponds to the subset of states of the controlled module, being retained in which does not lead to the resource (reserve share modules) exhaustion. In other words, $P\left\{S(t) \in \mathbb{E}_{R}\right\}$ is the probability that the random process will not attain the state $S_{F}$ during the time interval $[0, t]$ provided that at the beginning of this time interval it was in the state $S_{0}$. Accordingly $P\left\{S(t) \in \mathbb{E}_{R}\right\}=R_{a i}(t)$, this represents the probability of the no-failure operation of the controlled module. The methods for determining the probability $R_{a i}(t)$ of the no-failure operation of a wide class of controlled devices and systems are known and well-developed, for example [12,13].

To determine the probability $P\left\{S(t) \in \mathbb{E}_{0}\right\}$ (denote it by $R_{0 i}(t)$ ) of presence of the random process in the subset $\mathbb{E}_{0}$ of operable states, it is necessary to investigate the process of random transitions in each of its aggregated states.

In accordance with the graph of states and transitions shown in Fig. 1, the output of a random process beyond the subset of states $\mathbb{E}_{0}$ is performed either into the states that are related to the failures of the controlled module, or into the states that correspond to the scheduled program control of this module. Moreover, at random moments $\left\{t_{i}\right\}$, which are determined by the previous behavior of the random process, it goes back to the subset of states $\mathbb{E}_{0}$, which characterizes its cyclicity. The peculiarity of this process is that the values $T_{i}=t_{i}-t_{i-1}, i \geqslant 2$, which are related to the transitions from the states $S_{7}, S_{22}$ and $S_{23}$ to the subset of states $E_{0}$, are mutually independent and distributed equally; and at the moments of its transition into the subset of states $\mathbb{E}_{0}$, the following moment of transition of this process to the state $S_{7}$ is being rescheduled and the course of the process for $t>t_{i}$ does not depend on its history, i.e., on the course of the process for $t \leqslant t_{i}$. Therefore, the moments $t_{i}$ are regeneration points, and the process itself, which describes the behavior of this module in time, is regenerative [14, p. 45].

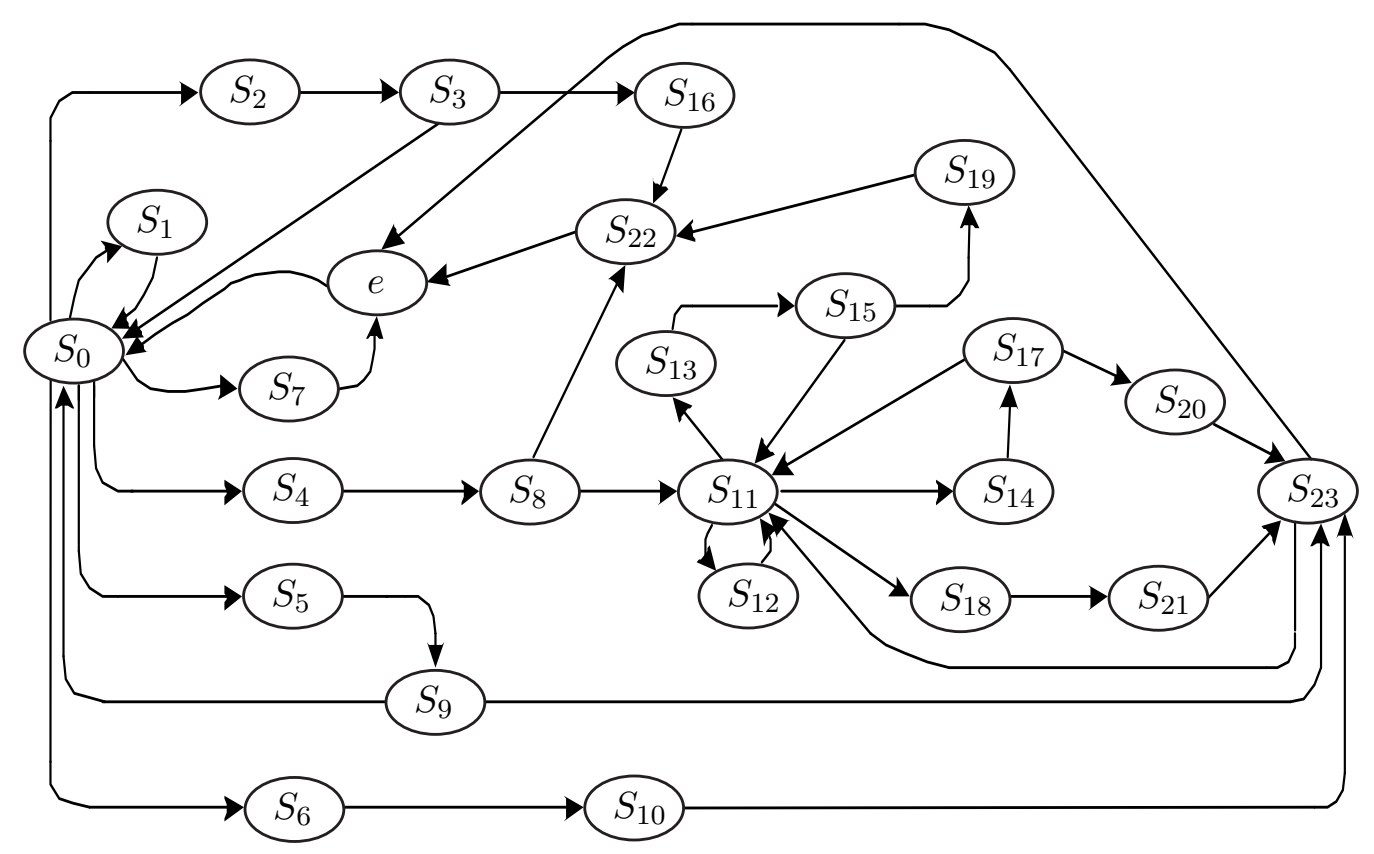

Fig. 3. Graph of states and transitions of random regeneration process. 
Using the graph of states and transitions which is shown in Fig. 1, we construct a graph of states and transitions of the regeneration process (Fig. 3). For the convenience of analyzing the regeneration process, we introduce the state $e$, entering which means a complete recovery of the random process. Assume that the average time of presence of this process in the state $e$ is zero. Note that the model of the controlled module (see Fig. 3) is described by two independent recovery processes [6, p. 50]. We denote them by $v(t)$ and $z(t)$. The process $v(t)$ corresponds to the recovery of the module after the detection of equipment failures and, as noted above, is regenerative, and the second process $z(t)$ corresponds to the recovery of the module from the consequences of faults. Since at the moments of entering the process $z(t)$ the state $S_{0}$, rescheduling of the moment of the following transition of the random process to the state $S_{7}$, is not being done, the specified moments are not points of regeneration, and the process $z(t)$ is not regenerative. Let $d H(t)$ be the probability that the regeneration period is on the time interval $[t, t+d t]$, and $S(t)$ is the state of this process at the moment $t$. Then

$$
R_{\mathrm{o} i}(t)=P\left\{S(t) \in \mathbb{E}_{0}\right\}=\int_{0}^{t} R_{1}\left\{S(0, t-x) \in \mathbb{E}_{0}\right\} d H(x) \cdot \int_{0}^{t} R_{2}\left\{S(0, t-x) \in \mathbb{E}_{0}\right\} d H(x),
$$

where $R_{1}\left\{S(0, t-x) \in \mathbb{E}_{0}\right\}$ and $R_{2}\left\{S(0, t-x) \in \mathbb{E}_{0}\right\}$ are the probabilities that on the interval $[0, t-x]$, the processes $v(t)$ and $z(t)$ will not go beyond the subset of operable states $\mathbb{E}_{0}$.

From [14, p. 26] we know that

$$
\int_{0}^{t} R\left\{S(0, t-x) \in \mathbb{E}_{0}\right\} d H(x)=R_{i}(t)
$$

Therefore

$$
R_{\mathrm{o} i}(t)=P\left\{S(t) \in \mathbb{E}_{0}\right\}=R_{1}(t) \cdot R_{2}(t),
$$

where $R_{1}(t)$ and $R_{2}(t)$ are the true values of the probabilities of presence of random processes $\nu(t)$ and $z(t)$, respectively, on the time interval $[0, t]$ in the subset of states $\mathbb{E}_{0}$.

In practice, the probabilities $R_{1}(t), R_{2}(t)$ are replaced by their stationary values. Then

$$
R_{\mathrm{o} i}(t)=R_{1} \cdot R_{2} .
$$

According to Smith's theorem [14, p. 26], we have

$$
R_{i}=\lim _{t \rightarrow \infty} \int_{0}^{t} R_{i}\left\{S(0, t-x) \in E_{0}\right\} d H(x)=T_{0}^{-1} \sum \bar{t}_{S_{0, i}}=\bar{t} T_{0}^{-1}
$$

where $\bar{t}_{S_{0 i}}$ and $\bar{t}$ are the average durations of the random process in the period $T_{0}$ of regeneration in the state $S_{0 i}\left(S_{0 i} \in \mathbb{E}_{0}\right)$ and in the subset of states $\mathbb{E}_{0}$, respectively.

Taking (2) into account, we obtain a formula for determining the probability of presence of a random process in the subset $E_{0}$ of the operable states:

$$
R_{\mathrm{o} i}=t_{v} \tilde{t}_{z} T_{0}^{-2}
$$

where $t_{v}$ and $\tilde{t}_{z}$ are the average durations of the random processes $\nu(t)$ and $z(t)$, respectively, in the period $T_{0}$ of regeneration in the subset $\mathbb{E}_{0}$ of the operable states.

From the expression (3) it follows that to determine the probability of presence of the random process in the subset $\mathbb{E}_{0}$ of the operable states, it is sufficient to conduct a time analysis of a random regenerating process whose graph of states and transitions is depicted in Fig. 3.

In the general case, the regeneration process is described using methods of theory of Markov or semi-Markov processes. The choice of a mathematical apparatus is determined by the properties of the states of the process being analyzed, i.e., by the shape of the function of distribution of its durations in the specified states, as well as by the dependence of the evolution of the process on a given state 
and on its duration in a given state [2, p. 86]. Above, when establishing the direction of transitions of the random process from state to state, it has been shown that the vast majority of its states have a semi-Markov property, which implies that the duration of a random process in a state depends on this state and does not depend on previous evolution. Exceptions are only the states $S_{4}, S_{6}$ and $S_{18}$, which are states of a two-dimensional Markov process, the first component of which describes the state of the process, and the second one fixes its duration in the states, i.e. the intervals between the moments of their change [11, p.5]. The properties of the specified states are a significant factor limiting the application of the theory of semi-Markov processes to the mathematical description of this model. It is known that if we extend in a certain way the states $S_{4}, S_{6}$ and $S_{18}$ by adding some possible states to them, in many cases it is possible to achieve that the new extended states will already have a semi-Markov property [11, p. 5]. As can be seen from the graph of states and transitions (see Fig. 3), a random process with the probability of a unit goes from the states $S_{4}, S_{6}$ and $S_{18}$ to the states $S_{8}$, $S_{10}$ and $S_{21}$, respectively. Therefore, the durations of the random process in the states $S_{4}, S_{6}$ and $S_{18}$ do not affect the average value of $T_{0}$ is the regeneration period, but affect only the average duration of the process in the state $S_{0}$. In this case, we come to a model whose all states have a semi-Markov property, which allows us to use the recovery equation of Markov to describe it. This equation for the average duration of a semi-Markov process in the discrete subset of states $\mathbb{E}[11$, p. 27] has the form

$$
T(i)-\sum_{j \in(\mathbb{E} \backslash e)_{i}} q(i, j) T(j)=\tau(i)
$$

where $T(i)$ and $T(j)$ are the average times before the transition of the semi-Markov process from the state $S_{i}$ and $S_{j}$, respectively, to the state $e, \tau(i)$ is the average duration of this process in the state $S_{i}$, $q(i, j)$ is the probability of the transition of the process from the state $S_{i}$ to the state $S_{j},(\mathbb{E} \backslash e)_{i}$ is the set of states of a semi-Markov process, except for the state $e$, into which its transition from the state $S_{i}$ is possible. The system of equations (4) is linear. To reduce its dimension, we transform the graph of states and transitions of the regeneration process.

Since when determining the average value of the $T_{0}$ regeneration period of a semi-Markov process, its states $S_{4}, S_{6}$ and $S_{18}$ are not taken into account, this allows combining the states $S_{7}, S_{8}$ and $S_{10}$, while preserving the transitions from these states to other states $\left(e, S_{11}, S_{22}, S_{23}\right)$. Similarly, we can combine the states $S_{2}$ and $S_{5}$; as a consequence, the states $S_{2}$ and $S_{5}$, as well as the states $S_{11}$ and $S_{12}, S_{13}$ and $S_{14}$; as a consequence, the states $S_{15}$ and $S_{17}, S_{19}$ and $S_{20}$. It should be noted that these transformations of the graph of states and transitions of a random regeneration process will be taken into account further in determining the parameters of a semi-Markov process (average times of its stay in specified states and probabilities of its transition from one state to another). Since the flows of failures and faults of a module are independent, the processes $\nu(t)$ and $z(t)$ are also independent. Therefore, we will analyze them individually.

\section{Defining the parameters of the failure process}

The graph of states and transitions of the process $\nu(t)$ is shown in Fig. 4, where $S_{0}$ corresponds to the functioning of the module in the absence of manifestation of failures; $S_{1}$ corresponds to the detection of failure of the controlled module by means of control hardware; $S_{2}$ corresponds to the functioning of the module according to the program of failure identification detected by the control hardware; $S_{3}$ corresponds to the termination of the module operation according to the main program and its transition to the scheduled program control regime; $S_{4}$ corresponds to the functioning of the module with the failure having been missed by hardware and software control; $S_{5}$ corresponds to the detection at the scheduled program control in the module, which previously failed, of a new failure; $S_{6}$ corresponds to the detection by hardware of a new failure of the module that failed earlier; $S_{7}$ corresponds to the transition of the module with the failure detected by the control hardware into unscheduled program control regime; $S_{8}$ corresponds to the restoration of the operability of hardware of the module control; 
$S_{9}$ corresponds to the restoration of performance of the controlled module; $S_{10}$ corresponds to the restoration of the operability of the module's control hardware having failed; $S_{11}$ corresponds to the detection at the scheduled program control of hardware failure of the controlled module, which failed before; $S_{12}$ corresponds to the transition of the module with the failure having been missed by means of hardware and software control to the mode of operation according to the program of identification of a new failure detected by its control hardware; $S_{13}$ corresponds to the transition of the module with the failure having been missed by means of hardware and software control to the mode of unscheduled program control due to the detection of new failures of this module by its control hardware.

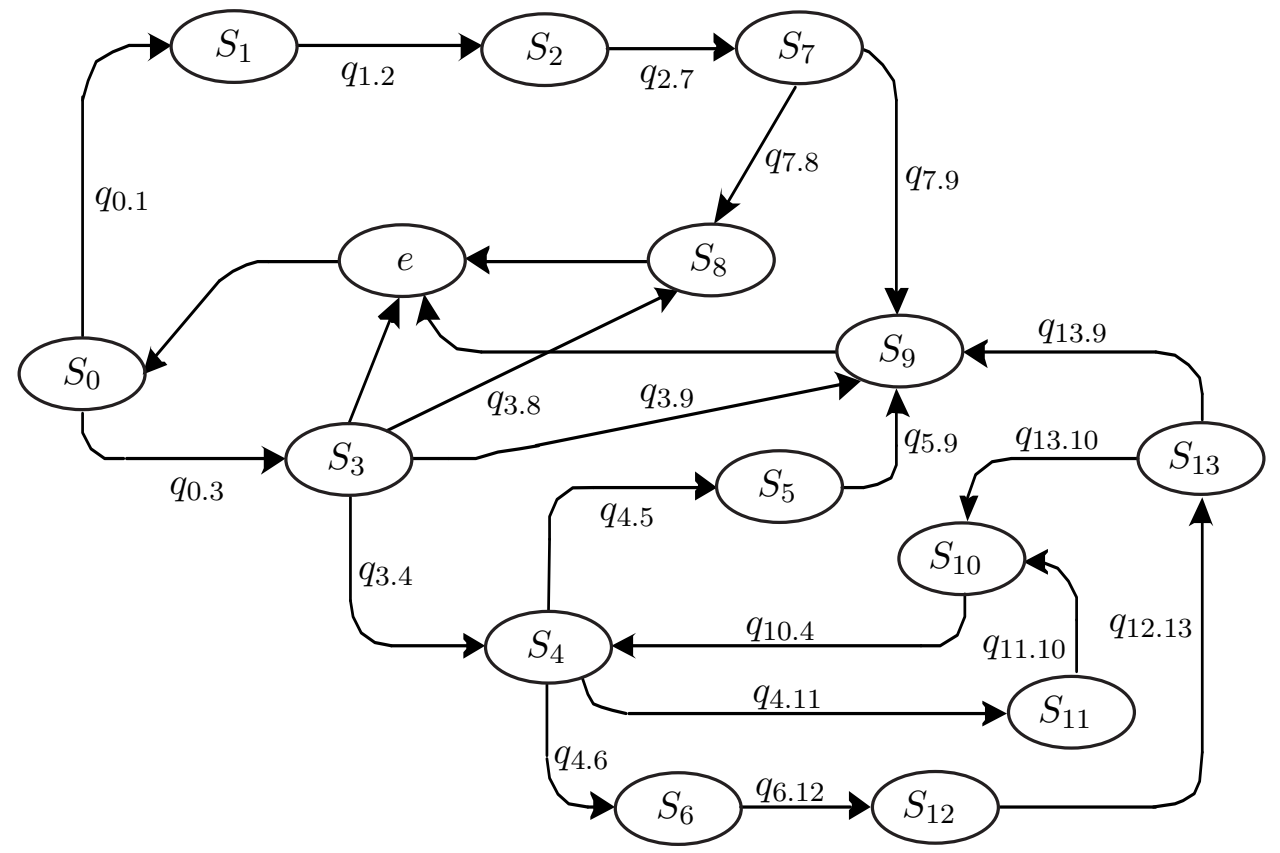

Fig. 4. Graph of states and transitions of random process $\nu(t)$.

By solving the corresponding system of Markov recovery equations, we obtain

$$
\begin{aligned}
T_{0}= & \tau_{0}+q_{0.1}\left(\tau_{1}+\tau_{2}+\tau_{7}+q_{7.8} \tau_{8}+q_{7.9} \tau_{9}\right)+q_{0.3}\left(\tau_{3}+q_{3.8} \tau_{8}+q_{3.9} \tau_{9}\right) \\
& +q_{0.3} q_{3.4}\left[\tau_{4}+q_{4.5}\left(\tau_{5}+\tau_{9}\right)+q_{4.6}\left(\tau_{6}+\tau_{12}+q_{13.9} \tau_{9}\right.\right. \\
& \left.\left.+q_{13.10} \tau_{10}+\tau_{13}\right)+q_{4.11}\left(\tau_{10}+\tau_{11}\right)\right] /\left(1-q_{4.11}-q_{4.6} \cdot q_{13.10}\right) .
\end{aligned}
$$

From the formulae (3) and (5), it follows that the probability $R_{\mathrm{o} i}$ of retaining of an arbitrary controlled module in the operable state is determined by its average duration in all specified states and by the probabilities of its transitions between them. Let us proceed to determining the mentioned parameters.

We will use the following notation. Denote by $\mathbb{S}=\left\{S_{0}, S_{1}, \ldots, S_{13}\right\}$ the set of states of the controlled module, and by $\mathbb{N}_{13}=\{1, \ldots, 13\}$ we denote the set of indices. For each state $S_{i}$ we denote by $\mathbb{E}_{i} \subset \mathbb{S}$ the subset of states into which the transition from the $S_{i}$ state is possible, and by the symbol $I_{i}$ we denote the set of states of the controlled module from which the transition to the $S_{i}$ state exists. We introduce the function $\delta(S), S \in \mathbb{S}$ as follows: $\delta(S)=1$, if $S \in \mathbb{S}$; otherwise $\delta(S)=0$. By this function we denote the set of the indices of states to which a transition from a given state $i$ is possible:

$$
I N\left(\mathbb{E}_{i}\right)=\left\{j \in \mathbb{N}_{13} \mid \delta(S) \neq 0, S \in \mathbb{E}_{i}\right\} .
$$

First, we determine the average duration $t_{\nu}$ of a semi-Markov process that describes the behavior of an arbitrary controlled module of a wireless communication system in the period $T_{0}$ of regeneration in the state $S_{0}$. This time corresponds to the functioning of the module without any manifestation of failures. To determine this time, we use the graph of states and transitions, which is shown in Fig. 3. 
According to the specified graph of states and transitions, the controlled module under the influence of the failure flow after the random time $\xi$, whose distribution function is $F(t)=P\{\xi \leqslant t\}$, transits from the state $S_{0}$ to one of the states of the set $\mathbb{E}_{0}=\left\{S_{2}, S_{4}, S_{5}, S_{6}, S_{7}\right\}$. The transition from the state $S_{0}$ to the state $S_{7}$, which corresponds to the scheduled program control of its correct functioning, is carried out during the time $\zeta=\zeta_{7}$, the distribution function of which is $G(t)=P\{\zeta \leqslant t\}$. Therefore, a random process that describes the behavior of a module in time transits in the direction of that flow in which the event has occurred earlier than in other flows. In other words, the random process is in the state $S_{0}$ until the first of the events, which transits it into one of the states of the subset $\mathbb{E}_{0}$. The controlled module is in this state over the time $\tau_{0}=\min \xi_{j}$, belonging to the subset $\mathbb{E}_{0}$, whose distribution function according to [2, p. 88] has the form $j \in I N\left(\mathbb{E}_{0}\right)$

$$
\psi_{0}(t)=P\left\{\min \left[\xi_{i} \mid i \in I N\left(\mathbb{E}_{0}\right)\right] \leqslant t\right\}=1-\prod_{\substack{S \in \mathbb{E}_{0} \\ i \in \mathbb{N}_{13}}}\left[1-\delta(S) F_{i}(t)\right]=1-\prod_{i \in I N\left(\mathbb{E}_{0}\right)}\left(1-F_{i}(t)\right),
$$

where $\xi_{i}$ is the random time from the moment of transition of the random process to the state $S_{0}$ until the moment of the first event occurs in each flow; $F_{i}(t)$ is the distribution function of the random time $\xi_{i}, F_{7}(t)=G(t)$. By using the formula (6), the relationships $\bar{G}(t)=1-G(t), \bar{F}_{i}(t)=1-F_{i}(t)$, and $I N\left(\mathbb{E}_{0}\right)=\{2,4,5,6,7\}$, we can write

$$
\psi_{0}(t)=1-\bar{F}_{2}(t) \cdot \bar{F}_{4}(t) \cdot \bar{F}_{5}(t) \cdot \bar{F}_{6}(t) \cdot \bar{G}(t) .
$$

Recently [2, p. 46], [15, p. 10] when modeling the flow of failures, the random variables have been applied, which are distributed according to the Weibull law. Its distribution function has the form $F(t)=1-e^{-\lambda_{0} t^{\alpha}}$, where $t$ is the time before the failure, $\lambda_{0}$ and $\alpha$ are parameters. The presence in the distribution of two parameters makes it possible to achieve a more complete correspondence of the theoretical distribution to the experimental data than in the case of the exponential law. Note [2, p. 46], [15, p. 10], for $\alpha<1$ the intensity $\lambda(t)$ of failures becomes a decreasing function of time, for $\alpha>1$ the Weibull distribution is characterized by an increasing in time failure rate. For electronic devices with the decreasing failure rate function [3, p. 21] $\alpha=0.2 \div 0.4$.

In contrast to the function $F(t)$, the function $G(t)$ that is also distributed by the Weibull law in which the parameter $\alpha$ is the same and the parameter $\lambda_{0}$ is unknown.

Since the random times $\left\{\xi_{j} \mid j \in I N\left(\mathbb{E}_{i}\right)\right\}$ correspond to the Weibull distribution with the parameters $\alpha_{i}$ and $\lambda_{0, i}$, i.e., $F_{i}(t)=1-\exp \left(-\lambda_{0, i} \cdot t^{\alpha_{i}}\right)$, and assuming that the parameters $\alpha_{1}=\alpha_{2}=, \ldots, \alpha_{7}=\alpha$ are the same, the expression (7) takes the form

$$
\psi_{0}(t)=1-\exp \left(-\lambda \cdot t^{\alpha}\right)
$$

where $\lambda=\sum_{i \in I N\left(\mathbb{E}_{0}\right)} \lambda_{0, i}$ is the total intensity of the random process transitions from the state $S_{0}$, and $\lambda_{0, i}$ is the intensity of its transitions from the state $S_{0}$ to the state $S_{i}$. The distribution function $G(t)$, as noted above, is also the Weibull distribution with the same parameter $\alpha$ and some parameter $\lambda_{0,7}$. Regarding the choice of the parameter $\lambda_{0,7}$, we will choose it experimentally from the condition of maximizing the average time of retaining the controlled module in operable condition. The transition intensities $\lambda_{0, i}$ of the random process correspond to the transition intensities of this module from the state $S_{0}$ and are determined by means of the parameters of the control methods used and of the reliable characteristics of this module and its hardware. The analytical relationships for determining the specified transition intensities are as follows:

$$
\begin{array}{ll}
\lambda_{0.2}=\lambda_{\mathrm{f}} p_{\mathrm{dfh}} ; & \lambda_{0.4}=\lambda_{\mathrm{f}}\left(1-p_{\mathrm{dfh}}\right) ; \\
\lambda_{0.5}=\lambda_{\text {ech } \alpha} ; & \lambda_{0.6}=\lambda_{\text {ech } \beta},
\end{array}
$$

where $\lambda_{\operatorname{ech} \alpha}$ and $\lambda_{\operatorname{ech} \beta}$ are the intensities of the transitions of the random process from the state $S_{0}$ to the states $S_{5}$ and $S_{6}$, respectively, which correspond to the failure rates of the control hardware which lead to errors of the first and second kinds, respectively. Note that here $\lambda_{\mathrm{f}}=\lambda_{\mathrm{fm}}+\lambda_{\mathrm{fch}}$. Taking the 
relationship (9) into account, we write the expression to determine the total intensity of transitions of a random process $\nu(t)$ from the state $S_{0}$

$$
\lambda=\lambda_{\mathrm{f}}+\lambda_{\mathrm{ech} \alpha}+\lambda_{\mathrm{ech} \beta}+\lambda_{0,7} .
$$

According to [11, p. 86], [16, p.70], the average duration of the semi-Markov process in the $i$-th state $\tau_{0}=\min \xi_{j}$, is determined by the formula $j \in I N\left(\mathbb{S}_{0}\right)$

$$
\tau_{i}=\int_{0}^{\infty} \psi_{i}(t) d t
$$

where $\psi_{i}(t)$ is the function of the distribution of the residence time of the semi-Markov process in the $S_{i}$ state. Using (8), we can write that

$$
\tau_{0}=t_{\nu}=\int_{0}^{\infty}\left\{1-\left[1-\exp \left(-\lambda \cdot t^{\alpha}\right)\right]\right\} d t=\Gamma\left(\frac{1}{\alpha}\right) \frac{\lambda^{-1 / \alpha}}{\alpha},
$$

where $\Gamma(x)=\int_{0}^{\infty} e^{-t} t^{x-1} d t$ is an Euler gamma function.

Now determine the average residence times $\tau_{i}$ of the semi-Markov process in the rest states. The controlled module from the state $S_{0}$, under the action of the failure flow detected by the control hardware can transit either to the state $S_{1}$, or at the time of the following scheduled program control of the correct functioning of this module it can transit to the state $S_{3}$. The semi-Markov process is in the state $S_{0}$ until the first of the events occurs, which transfers it into one of the states $S_{1}$ or $S_{3}$, and retains in it over the minimal of $\xi_{1}$ and $\xi_{3}$ time, whose the distribution function is determined by the expression (6).

$$
\psi_{0}(t)=P\left\{\min \left(\xi_{1}, \xi_{3}\right) \leqslant t\right\}=1-\left(1-F_{1}(t)\left(1-F_{3}(t)\right)=1-\bar{F}_{1} \cdot \bar{F}_{3} .\right.
$$

Using the expression (11) and the relationship $F_{3}(t)=G(t)$, we can write

$$
\psi_{0}(t)=1-\bar{F}_{1}(t) \cdot \bar{G}(t) .
$$

Since the random times $\xi_{1}$ and $\xi_{3}$ correspond to the Weibull distribution with the parameters $\alpha$ and $\lambda_{0, i}$, i.e., $F(t)=1-\exp \left(\lambda_{0, i} \cdot t^{\alpha}\right)$, and taking the parameters $\alpha$ to be equal, the expression (12) takes the following form:

$$
\psi_{0}(t)=1-\exp \left(-\lambda_{1} \cdot t^{\alpha}\right),
$$

where $\lambda_{1}=\sum_{i \in I N\left(\mathbb{E}_{0}\right)} \lambda_{0, i}$ is the total intensity of the random process transitions from the state $S_{0}$, $\lambda_{0, i}$ is the intensity of its transitions from the state $S_{0}$ to the state $S_{i}$.

The intensity of transitions $\lambda_{0,1}$ of the random process corresponds to the intensity of transitions of this module from the state $S_{0}$ to the state $S_{1}$ and is determined by means of the parameters of the control methods used and of the reliable characteristics of this module and its control hardware. Thus, we have

$$
\lambda_{0.1}=\left(\lambda_{\mathrm{f}}+\lambda_{\mathrm{ech} \alpha}\right) p_{\mathrm{dfh}} .
$$

The total intensity of transitions of a random process from the state $S_{0}$ is as follows:

$$
\lambda_{1}=\left(\lambda_{\mathrm{f}}+\lambda_{\mathrm{ech} \alpha}\right) p_{\mathrm{dfh}}+\lambda_{0.3}
$$

Regarding the choice of the parameter $\lambda_{0.3}$, we will choose it experimentally from the condition of maximizing the average residence time of the controlled module in operable condition.

Taking into account (10) and (13), we can write

$$
\tau_{0}=\int_{0}^{\infty}\left\{1-\left[1-\exp \left(-\lambda_{1} \cdot t^{\alpha}\right)\right]\right\} d t=\int_{0}^{\infty} \exp \left(-\lambda_{1} \cdot t^{\alpha}\right) d t=\Gamma\left(\frac{1}{\alpha}\right) \frac{\lambda_{1}^{-1 / \alpha}}{\alpha} .
$$

Mathematical Modeling and Computing, Vol. 6, No. 2, pp. 192-210 (2019) 
The average residence times $\tau_{1}, \tau_{2}, \tau_{3}$ of the semi-Markov process in the respective states $S_{1}, S_{2}, S_{3}$ correspond to the average times of detection of the control module failure by the control hardware $t_{\mathrm{fdch}}$, identification of detected failures $t_{\mathrm{id}}$, and of the software control of the correct functioning of the controlled module $t_{\mathrm{sc}}$, respectively.

It is mentioned above that $t_{\text {fdch }}=0$. Therefore $\tau_{1}=t_{\text {fdch }}=0$. The average times $\tau_{2}=t_{\text {id }}$ and $\tau_{3}=t_{\mathrm{sc}}$ are random variables with an arbitrary distribution function $K(t)=P\{\chi \leqslant t\}$ and $H(t)=P\{\varsigma \leqslant t\}$, respectively. The time $\tau_{2}=t_{\text {id }}$ represents the average time of failure identification. One of the most widespread and fully complying with the requirements of engineering practice of the laws of the distribution of time necessary to control the correct functioning of radio-electronic equipment, troubleshooting, repairing and its restoration is a lognormal distribution [2, p. 50], [17, p. 38]. Taking the average time of identification of failures to be distributed according to a lognormal law with the parameters $(\mu, \sigma)$, where $\mu, \sigma$ are the parameters of the shape and scale of lognormal distribution, we obtain:

$$
\tau_{i}=t_{\text {id }}=M_{\chi_{i}}=\int_{0}^{\infty} t f_{i}(t) d t=\frac{1}{\sigma \sqrt{2 \pi}} \int_{0}^{\infty} \exp \left[-\frac{(\ln t-\mu)^{2}}{2 \sigma^{2}}\right] d t=e^{\mu+\sigma^{2} / 2}, \quad i \in\{2,12\}
$$

if

$$
f_{i}(t)=(t \sigma \sqrt{2 \pi})^{-1} \exp \left\{-(\ln t-\mu)^{2}\left(2 \sigma^{2}\right)^{-1}\right\}
$$

where $f_{i}(t)$ is the probability density of the lognormal distribution, $\sigma$ and $\mu$ are the distribution parameters.

The average residence times $\tau_{3}, \tau_{5}, \tau_{7}, \tau_{11}, \tau_{13}$ of the semi-Markov process in the states $S_{3}, S_{5}, S_{7}, S_{11}$, and $S_{13}$, respectively, correspond to the average duration $t_{\mathrm{sc}}$ of the program control, and the average residence time $\tau_{6}$ in the state $S_{6}$ corresponds to the average time $t_{f d c h}$ of detection of the failures of the controlled module by its control hardware.

It is stated above that the distribution of the time required to perform the program control of the correct functioning of the controlled module is lognormal. Therefore, similarly to (16) and taking into account that the average time of program control is distributed according to the lognormal law with other parameters $\left(\sigma_{1}, \mu_{1}\right)$, we obtain:

$$
\tau_{i}=t_{\mathrm{sc}}=M_{\varsigma_{i}}=\frac{1}{\sigma_{1} \sqrt{2 \pi}} \int_{0}^{\infty} \exp \left[-\frac{\left(\ln t-\mu_{1}\right)^{2}}{2 \sigma_{1}^{2}}\right] d t=e^{\mu_{1}+\sigma_{1}^{2} / 2}, \quad i \in\{3,5,7,11,13\},
$$

where $f_{i}(t)$ is the probability density, which is determined by the formula (17).

Since the average time $\tau_{6}$ corresponds to the average time $t_{\text {fdch }}$ of detection of failure by the control hardware, according to the assumption above, it can be written that $\tau_{6}=t_{\text {fdch }}=0$.

As it can be seen from the graph of states (Fig. 4), the semi-Markov process is being in the state $S_{4}$ until the first of the events occurs which transfers it into one of the states of the subset $\mathbb{E}_{4}$. The controlled module retains in this state over the time $\tau_{4}=\underset{j \in I N\left(\mathbb{E}_{4}\right)}{\min \xi_{j}}$, belonging to the subset $\mathbb{E}_{4}$ whose distribution function, according to (6), is of the form:

$$
\psi_{4}(t)=P\left\{\min \left[\xi_{j} \mid j \in I N\left(\mathbb{E}_{4}\right)\right] \leqslant t\right\}=1-\prod_{\substack{S \in \mathbb{E}_{4} \\ i \in \mathbb{N}_{13}}}\left[1-\delta(S) F_{i}(t)\right]=1-\bar{F}_{5}(t) \cdot \bar{F}_{6}(t) \cdot \bar{F}_{11}(t)
$$

Since the times before the transition of the semi-Markov process from the state $S_{4}$ to the states $S_{5}$, $S_{6}$ and $S_{11}$ are distributed by the Weibull law with the same parameter $\alpha$, the expression (18) can be written in the following form:

$$
\psi_{4}(t)=1-\exp \left(-\lambda_{2} \cdot t^{\alpha}\right)
$$

where $\lambda_{2}=\sum_{i \in I N\left(\mathbb{E}_{4}\right)} \lambda_{4, i}$ is the total intensity of transitions of the semi-Markov process from the state $S_{4}$, and $\lambda_{4 . i}$ is the intensity of its transitions from the state $S_{4}$ to the state $S_{i}, i \in I N\left(\mathbb{E}_{4}\right)$. 
The transitions intensities $\lambda_{4 . i}$ are determined by the parameters $\lambda_{\mathrm{f}}, \lambda_{\operatorname{ech} \alpha}$ and by the parameters of the flow of random events which correspond to the reliable characteristics of the controlled module and its controls. Analytical relationships for determining the intensities of transitions of the semi-Markov process are:

$$
\lambda_{4.5}=\left(\lambda_{\mathrm{f}}+\lambda_{\mathrm{ech} \alpha}\right) p_{\mathrm{fds}} ; \quad \lambda_{4.6}=\left(\lambda_{\mathrm{f}}+\lambda_{\mathrm{ech} \alpha}\right) p_{\mathrm{dfh}} ; \quad \lambda_{4.11}=\left(\lambda_{\mathrm{fch}}+\lambda_{\mathrm{ech} \alpha}\right) p_{\mathrm{fds}},
$$

where $\lambda_{\text {fch }}$ is the failure rate of hardware to control the correct functioning of the controlled module.

Taking into account the relations (10) and (19), the average residence time $\tau_{4}$ of the semi-Markov process in the state $S_{4}$ is determined by the formula

$$
\tau_{4}=\int_{0}^{\infty}\left\{1-\left[1-\exp \left(-\lambda_{2} \cdot t^{\alpha}\right)\right]\right\} d t=\int_{0}^{\infty} \exp \left(-\lambda_{2} \cdot t^{\alpha}\right) d t=\Gamma\left(\frac{1}{\alpha}\right) \frac{\lambda_{2}^{-1 / \alpha}}{\alpha} .
$$

Using the relationship (20), we write an expression to determine the total intensity $\lambda_{2}$ of transitions of the random process $v(t)$ from the state $S_{4}$

$$
\lambda_{2}=\left(\lambda_{\mathrm{f}}+\lambda_{\text {ech } \alpha}\right)\left(p_{\mathrm{fds}}+p_{\mathrm{dfh}}\right)+\left(\lambda_{\mathrm{fch}}+\lambda_{\mathrm{ech} \alpha}\right) p_{\mathrm{fds}} .
$$

The average residence times $\tau_{8}, \tau_{10}$ of the semi-Markov process in the states $S_{8}$ and $S_{10}$, respectively, correspond to the average recovery time $t_{\mathrm{rch}}$ of the hardware to control the correct functioning of the controlled module, and the average residence time $\tau_{9}$ of the semi-Markov process in the state $S_{9}$ corresponds to the average recovery time $t_{\mathrm{rhm}}$ of the operability of the controlled module, i.e., $\tau_{8}=$ $\tau_{10}=t_{\mathrm{rch}}$ and $\tau_{9}=t_{\mathrm{rhm}}$. The indicated times are continuous random variables with the distribution function $L(t)=P\{\eta \leqslant t\}$.

Similarly to (16), and taking into account that the average recovery time of the controlled module and its control hardware is distributed by the lognormal law with other parameters $\left(\sigma_{2}, \mu_{2}\right)$, we obtain:

$$
\tau_{i}=t_{\mathrm{rch}}=t_{\mathrm{rhm}}=M_{\eta_{i}}=\frac{1}{\sigma_{2} \sqrt{2 \pi}} \int_{0}^{\infty} \exp \left[-\frac{\left(\ln t-\mu_{2}\right)^{2}}{2 \sigma_{2}^{2}}\right] d t=e^{\mu_{2}+\sigma_{2}^{2} / 2}, \quad i \in\{8,9,10\} .
$$

Knowing the average residence time of the semi-Markov process in all specified states $S_{i}$, as well as the intensities of its transitions between them, we proceed to determining the probabilities of the transitions $q_{i . j}$ of this process between the specified states.

It is known [2, p. 75] that the probability of transition of a semi-Markov process from the state $S_{i}$ to the state $S_{j}$ is determined by the formula

$$
q_{i . j}(t)=\int_{0}^{\infty} p(t ; i . j) d \psi_{i}(t)
$$

where $p(t ; i . j)$ is the conditional probability of transition of a semi-Markov process from the state $S_{i}$ to the state $S_{j}$ provided that at the moment $t$ it was in the state $S_{i}$, and $\psi_{i}(t)$ is the function of distribution of residence time of the semi-Markov process in the state $S_{i}$.

Since the time of transition of the semi-Markov process from the state $S_{0}$ to the state $S_{1}$ is distributed by the Weibull law, the probability of transition of this process from the state $S_{0}$ to the state $S_{1}$ is determined by the formula

$$
q_{0.1}=\int_{0}^{\infty} \exp \left(-\lambda_{0.1} \cdot t^{\alpha}\right) d \psi_{0}(t)
$$

where $\psi_{0}(t)$ is determined by the formula (13), and the transition intensity $\lambda_{0.1}$ of the semi-Markov process from the state $S_{0}$ to the state $S_{1}$ is determined by the formula (14).

Since $d \psi_{0}(t)=\lambda_{1} \alpha t^{\alpha-1} \exp \left(-\lambda_{1} t^{\alpha}\right) d t$, then

$$
q_{0.1}=\int_{0}^{\infty} e^{-\lambda_{0.1} \cdot t^{\alpha}} \lambda_{1} \alpha t^{\alpha-1} e^{-\lambda_{1} \cdot t^{\alpha}} d t=\lambda_{1}\left(\lambda_{1}+\lambda_{0.1}\right)^{-1}
$$

Mathematical Modeling and Computing, Vol. 6, No. 2, pp. 192-210 (2019) 
The total intensity $\lambda_{1}$ of transitions of a random process from the state $S_{0}$ is determined by the formula (15). According to the graph of states and transitions of the semi-Markov process $v(t)$ (Fig. 4), the transition probabilities $q_{0.1}$ and $q_{0.3}$ form a complete group of events. Therefore, we can write $q_{0.3}=1-q_{0.1}$.

From the state $S_{3}$, the controlled module can transit to the state $S_{9}$ or $S_{9}$ (if during the period $T$ of the program control of its correct functioning there occurs a failure of the controlled module or its control hardware, which will be missed by these control hardware), or to the state $S_{4}$ (if failure of the controlled module will be missed even at scheduled program control of its correct functioning). With this, the probability that a failure of the controlled module to occur during the program control period and will not be detected by the hardware control can be determined by the formula

$$
p_{\mathrm{sc}}=\int_{0}^{\infty}\left\{1-\left[1-\exp \left(-\lambda_{\mathrm{fm} \beta} \cdot t^{\alpha}\right)\right]\right\} d \psi_{3}(t)
$$

where $\lambda_{\mathrm{fm} \beta}$ is the failures rate of the controlled module that are not detected by the control hardware. Analytical relationships for determining the intensities of transitions of the semi-Markov process from the state $S_{3}$ are as follows:

$$
\begin{gathered}
\lambda_{3.4}=\left(\lambda_{\mathrm{f}}+\lambda_{\text {ech } \alpha}\right)\left(1-p_{\mathrm{dfh}}\right)\left(1-p_{\mathrm{fds}}\right) ; \quad \lambda_{3.8}=\left(\lambda_{\mathrm{fch}}+\lambda_{\text {ech } \alpha}\right)\left(1-p_{\mathrm{dfh}}\right) ; \\
\lambda_{\mathrm{fm} \beta}=\lambda_{3.9}=\left(\lambda_{\mathrm{f}}+\lambda_{\text {ech } \alpha}\right)\left(1-p_{\mathrm{dfh}}\right)+\lambda_{\mathrm{ech} \beta} .
\end{gathered}
$$

As it can be seen from the graph of states and transitions (Fig. 4), the semi-Markov process retains in the state $S_{3}$ until the first of the events occurs which transfers it into one of the states of the subset $E_{3}$. Thus

$$
\psi_{3}(t)=1-\bar{F}_{4}(t) \cdot \bar{F}_{8}(t) \cdot \bar{F}_{9}(t)
$$

Since the times before the transition of the semi-Markov process from the state $S_{3}$ to the states $S_{4}$, $S_{8}$ and $S_{9}$ have the Weibull distribution with the same parameter $\alpha$, the expression for the determination of $\psi_{3}(t)$ can be written in the following form:

$$
\psi_{3}(t)=1-\exp \left(-\lambda_{3} \cdot t^{\alpha}\right)
$$

where $\lambda_{3}=\sum_{i \in I N\left(\mathbb{E}_{3}\right)} \lambda_{3 . i}$ is the total intensity of transitions of the semi-Markov process from the state $S_{3}$, and $\lambda_{3, i}$ is the intensity of its transitions from the state $S_{3}$ to the state $S_{i}, i \in I N\left(\mathbb{E}_{3}\right)$. Given the relation (23), we write the expression to determine the total intensity of transitions $\lambda_{3}$ of a random process from the state $S_{3}$ :

$$
\lambda_{3}=\left(1-p_{\mathrm{dfh}}\right)\left\{\left(\lambda_{\mathrm{f}}+\lambda_{\mathrm{ech} \alpha}\right)\left[\left(1-p_{\mathrm{fds}}\right)+1\right]+\lambda_{\mathrm{fch}}+\lambda_{\mathrm{ech} \alpha}\right\}+\lambda_{\operatorname{ech} \beta} .
$$

Since the time of transition of a semi-Markov process from the state $S_{3}$ to the state $S_{9}$ is distributed by the Weibull law, the probability $q_{3.9}$ of transition of this process from the state $S_{3}$ to state $S_{9}$ is determined by the formula

$$
q_{3.9}=\int_{0}^{\infty} \exp \left(-\lambda_{3.9} \cdot t^{\alpha}\right) d \psi_{3}(t)
$$

Since $d \psi_{3}(t)=\lambda_{3} \alpha t^{\alpha-1} \exp \left(-\lambda_{3} t^{\alpha}\right) d t$

$$
q_{3.9}=\int_{0}^{\infty} e^{-\lambda_{3.9} \cdot t^{\alpha}} \lambda_{3} \alpha t^{\alpha-1} e^{-\lambda_{3} \cdot t^{\alpha}} d t=\lambda_{3}\left(\lambda_{3}+\lambda_{3.9}\right)^{-1}
$$

Similarly, we define the transition probability $q_{3.8}=\lambda_{3}\left(\lambda_{3}+\lambda_{3.8}\right)^{-1}$. Since the transition probabilities $q_{3.4}, q_{3.8}$ and $q_{3.9}$ form a complete group of events, $q_{3.4}=1-q_{3.8}-q_{3.9}$.

Analytical relations for determining the transient intensities of the semi-Markov process from the state $S_{4}$ are given in (20). As can be seen from the graph of states and transitions (Fig. 4), the semi- 
Markov process retains in the state $S_{4}$ until the first of the events occurs which transfers it into one of the states of the subset $\mathbb{E}_{4}$. Thus

$$
\psi_{4}(t)=1-\bar{F}_{5}(t) \cdot \bar{F}_{6}(t) \cdot \bar{F}_{11}(t) .
$$

Since the transition times of the semi-Markov process from the state $S_{4}$ to the states $S_{5}, S_{6}$ and $S_{11}$ are distributed by the Weibull law with the same parameter $\alpha$, the expression for the determining $\psi_{4}(t)$ can be written in the following form:

$$
\psi_{4}(t)=1-\exp \left(-\lambda_{2} \cdot t^{\alpha}\right)
$$

where $\lambda_{2}$ is determined according to the formula (21).

Since the time of transition of the semi-Markov process from the state $S_{4}$ to the state $S_{5}$ is distributed by the Weibull law, the probability $q_{4.5}$ of transition of this process from the state $S_{4}$ to the state $S_{5}$ is determined by the formula

$$
q_{4.5}=\int_{0}^{\infty} \exp \left(-\lambda_{4.5} \cdot t^{\alpha}\right) d \psi_{4}(t)
$$

Since $d \psi_{4}(t)=\lambda_{2} \alpha t^{\alpha-1} \exp \left(-\lambda_{2} t^{\alpha}\right) d t$

$$
q_{4.5}=\int_{0}^{\infty} e^{-\lambda_{4.5} \cdot t^{\alpha}} \lambda_{2} \alpha t^{\alpha-1} e^{-\lambda_{2} \cdot t^{\alpha}} d t=\lambda_{2}\left(\lambda_{2}+\lambda_{4.5}\right)^{-1}
$$

Similarly, we define the transition probability $q_{4.6}=\lambda_{2}\left(\lambda_{2}+\lambda_{4.6}\right)^{-1}$. The transition probabilities $q_{4.5}, q_{4.6}$ and $q_{4.11}$ form a complete group of events. Therefore $q_{4.11}=1-q_{4.5}-q_{4.6}$.

The probability $q_{7.8}$ of transition of the semi-Markov process from the state $S_{7}$ to the state $S_{8}$ is determined by the formula

$$
q_{7.8}=\int_{0}^{\infty}\left[1-\exp \left(-\lambda_{\mathrm{df}} t^{\alpha}\right)\right] d H(t)=\frac{1}{\sigma_{2} \sqrt{2 \pi}} \int_{0}^{\infty}\left[1-\exp \left(-\lambda_{\mathrm{df}} t^{\alpha}\right)\right] \exp \left[-\frac{\left(\ln t-\mu_{2}\right)^{2}}{2 \sigma_{2}^{2}}\right] \frac{d t}{t},
$$

where $\lambda_{\mathrm{df}}$ is the intensity of detected failures $\left(\lambda_{\mathrm{df}}=\lambda_{\mathrm{f}} \cdot p_{\mathrm{dfh}}\right), H(t)$ is the lognormal distribution law with parameters $\left(\sigma_{2}, \mu_{2}\right)$, and $q_{7.9}=1-q_{7.8}$ because the probabilities of transitions $q_{7.8}$ and $q_{7.9}$ form a complete group of events.

By analogy

$$
q_{13.9}=\int_{0}^{\infty}\left[1-\exp \left(-\lambda_{13.9} t^{\alpha}\right)\right] d H(t)=\frac{1}{\sigma_{2} \sqrt{2 \pi}} \int_{0}^{\infty}\left[1-\exp \left(-\lambda_{13.9} t^{\alpha}\right)\right] \exp \left[-\frac{\left(\ln t-\mu_{2}\right)^{2}}{2 \sigma_{2}^{2}}\right] \frac{d t}{t},
$$

where $\lambda_{13.9}=\lambda_{\mathrm{f}} \cdot p_{\mathrm{fds}}, q_{13.10}=1-q_{13.9}$. Thus, we have obtained the average residence times in the specified states and the probabilities of transitions between them for a random process $v(t)$.

\section{Determining the parameters of the process of faults}

Let us proceed to determining the parameters of a random process $z(t)$ of restoring a controlled module from the consequences of faults. The graph of states and transitions of this process is shown in Fig. 5 .

The states of the random process $z(t)$ correspond to the following states of the controlled module. $S_{0}$ corresponds to the functioning of the module in the absence of faults; $S_{1}$ corresponds to the functioning of the module with a missed

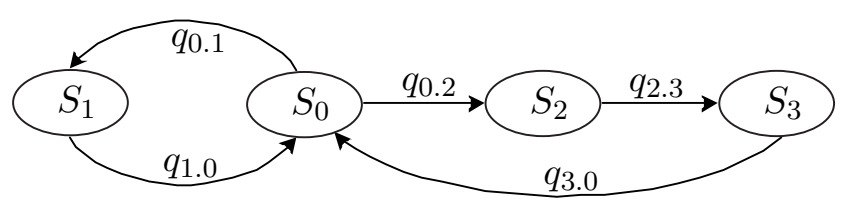

Fig. 5. Graph of states and transitions of random process $z(t)$. 
fault; $S_{2}$ corresponds to the detection by hardware means of a hardware fault of the controlled module; $S_{3}$ corresponds to the restoration of the controlled module of a fault having been detected by the module's hardware control.

To distinguish between the parameters (average residence times $\tau_{i}$ of a random process in the specified states $S_{i}$ and the probability of transitions $q_{i . j}$ of this process between them) of the semiMarkov processes $v(t)$ and $z(t)$, we denote the indicated process $z(t)$ parameters by a wavy line from above.

First, by analogue to the previous section, by solving a linear system of Markov recovery equations, we find

$$
\tilde{T}_{0}=\tilde{T}_{\mathrm{rec}}=\left(\tilde{\tau}_{0}+\tilde{q}_{0.1} \cdot \tilde{\tau}_{1}+\tilde{q}_{0.2} \cdot \tilde{\tau}_{3}\right) /\left(1-\tilde{q}_{0.1}\right)
$$

where $\tilde{T}_{\text {rec }}$ is a period of recovery of the controlled module from the consequences of failure.

Determine the average residence times $\tau_{i}$ of the semi-Markov process $z(t)$ in the specified states.

The controlled module is in a state $S_{0}$ over the time $\tau_{0}=\underset{j \in I N\left(S_{0}\right)}{\min \xi_{j}}$, which belongs to the subset $\mathbb{E}_{0}$, the distribution function of which is determined by the formula (6):

$$
\tilde{\psi}_{0}(t)=P\left\{\min \left[\xi_{j} \mid j \in I N\left(S_{0}\right)\right] \leqslant t\right\}=1-\prod_{j \in I N\left(S_{0}\right)}\left(1-\tilde{F}_{j}(t)\right)
$$

To simulate the fault of the equipment of a telecommunication system, we use the Erlang distribution with parameters $(\tilde{n}, \tilde{\mu}), \tilde{n}$ is a natural number (order of distribution), and $\tilde{\mu} \in(0, \infty)$. That is, the random variables $\xi_{j}, j \in I N\left(S_{0}\right)$ are random variables with the following distribution function

$$
\tilde{F}_{j}(t)=\tilde{F}(t)=1-e^{-\tilde{\mu} t} \sum_{k=0}^{\tilde{n}-1} \frac{(\tilde{\mu} t)^{k}}{k !} .
$$

Therefore

$$
\tilde{\psi}_{0}(t)=1-(1-\tilde{F}(t))^{2}=1-\left(e^{-\tilde{\mu} t} \sum_{k=0}^{\tilde{n}-1} \frac{(\tilde{\mu} t)^{k}}{k !}\right)^{2} .
$$

According to (10), let us calculate the average residence time $\tilde{\tau}_{0}$ of the process $z(t)$ in the state $S_{0}$.

$$
\begin{aligned}
\tilde{\tau}_{0} & =\int_{0}^{\infty} \exp (-\tilde{\mu} t) \sum_{k=0}^{\tilde{n}-1} \frac{(\tilde{\mu} t)^{k}}{k !} d t=\sum_{k=0}^{\tilde{n}-1} \int_{0}^{\infty} \frac{(\tilde{\mu} t)^{k}}{k !} e^{-\tilde{\mu} t} d t \\
& =\sum_{k=0}^{\tilde{n}-1} \frac{1}{\tilde{\mu} k !} \int_{0}^{\infty} x^{k} e^{-x} d x=\frac{1}{\tilde{\mu}} \sum_{k=0}^{\tilde{n}-1} \frac{\Gamma(k+1)}{k !}=\frac{\tilde{n}}{\tilde{\mu}} .
\end{aligned}
$$

Assuming that the time of execution of tasks by a controlled module is distributed according to the normal law with parameters $\left(\tilde{a}, \tilde{\sigma}^{2}\right)$, we obtain that $\tilde{\tau}_{1}=\tilde{a}$, where $\tilde{a}$ is the average value of the random variable, and $\tilde{\sigma}^{2}$ is its mean deviation.

The average residence time $\tilde{\tau}_{2}$ of the process $z(t)$ in the state $S_{2}$ amounts to $t_{\mathrm{fdch}}$, i.e., $\tilde{\tau}_{2}=t_{\mathrm{fdch}}=0$.

Given that the average recovery time $\tilde{\tau}_{3}$ of the controlled module from the consequences of faults is distributed by a lognormal law with the parameters $(\tilde{\mu}, \tilde{\sigma})$, we obtain:

$$
\begin{aligned}
\tilde{\tau}_{3} & =\tilde{t}_{\mathrm{rec}}=\tilde{M}_{3}=\int_{0}^{\infty} t f_{3}(t) d t \\
& =\frac{1}{\tilde{\sigma} \sqrt{2 \pi}} \int_{0}^{\infty} \exp \left[-\frac{(\ln t-\tilde{\mu})^{2}}{2 \tilde{\sigma}^{2}}\right] d t=e^{\tilde{\mu}+\tilde{\sigma}^{2} / 2} .
\end{aligned}
$$

Mathematical Modeling and Computing, Vol. 6, No. 2, pp. 192-210 (2019) 
The probabilities of transitions $\tilde{q}_{0.2}$ are determined according to $(22)$, in which the probabilities included in $(22)$ are distributed by the Erlang law with the same parameters $(\tilde{n}, \tilde{\mu})$. We have

$$
\tilde{q}_{0.2}=2 \tilde{\mu} \int_{0}^{\infty}\left(1-e^{-\tilde{\mu} t} \sum_{k=0}^{\tilde{n}-1} \frac{(\tilde{\mu} t)^{k}}{k !}\right) e^{-2 \tilde{\mu} t} \sum_{k=0}^{\tilde{n}-1} \frac{(\tilde{\mu} t)^{k+\tilde{n}-1}}{(\tilde{n}-1) ! k !} d t .
$$

According to the graph of states and transitions of the semi-Markov process $z(t)$ (Fig. 5). The transitive probabilities $\tilde{q}_{0.1}$ and $\tilde{q}_{0.2}$ form a complete group of events. Therefore $\tilde{q}_{0.1}=1-\tilde{q}_{0.2}$.

Since the average stay of the random process $z(t)$ in the state $S_{0}$ over the period $\tilde{T}_{\text {rec }}$ amounts to $\tilde{\tau}_{0}$, the average residence time $t_{z}$ of the random process $z(t)$ over the period $T_{0}$ of regeneration in the state $S_{0} t_{z}=\tilde{\tau}_{0} T_{0} \tilde{T}_{\text {rec }}^{-1}=\tilde{N} \tilde{\tau}_{0}$, where $\tilde{N}$ is the number of detected failures of the controlled module during the regeneration period $T_{0}$.

Thus, finding the main features of the semi-Markov process is completed. The probability of the stay of an arbitrary controlled module of the telecommunication system in the subset $\mathbb{E}_{0}$ of the operable states is also obtained.

\section{Conclusions}

A reliability semi-Markov model has been constructed for a wireless telecommunication system with a complex control system. An analytical expression has been obtained to estimate the probability of retaining an arbitrary controlled module of the system in its operable state. This expression is described by the parameters of a semi-Markov process (the average duration of this process in the specified states and the probabilities of its transitions between them), which are fully determined in terms of the reliability characteristics of the controlled module and in terms of the corresponding characteristics of the used means of control of its correct functioning.

The constructed semi-Markov reliability model will be used during the system design of highreliability systems of wireless telecommunication.

[1] Volochij B. V., Kalashnikov I. D., Mazepa R. B., Mandzij B. A. Proektirovanie otkazoustojchivyh mikroprocessornyh informacionno-izmeritel'nyh sistem. Lvov, Vyshha shkola (1987), (in Russian).

[2] Zhuravljov Yu. P., Koteljuk L. A., Ciklinskij N. I. Nadjozhnost' i kontrol' EVM. Moskva, Sovetskoe radio (1978), (in Russian).

[3] Koteljuk L. A., Trusov V.A. Ocenka dostovernosti funkcionirovaniya processora s kompleksnoj sistemoj kontrolya. Avtomatika i vychislitel'naya tehnika. 4, 49-52 (1973), (in Russian).

[4] Bobalo Yu. Ya., Volochii B. Yu., Lozynskyi O. Yu., Mandzii B. A., Ozirkovskyi L. D., Fedasiuk D. V., Shcherbovskykh S. V., Yakovyna V. S. Matematychni modeli ta metody analizu nadiinosti radioelektronnykh, elektrotekhnichnykh ta prohramnykh system. Lviv, Vydavnytstvo Lvivskoi politekhniky (2013), (in Ukrainian).

[5] Volochiy B., Yakubenko V., Zmysnyi M. Reliability model of fault-tolerant system based on the majority structure 3 of 5 with combined structural redundancy and maintenance. Visnyk Natsionalnoho universytetu "Lvivska politekhnika". Serie: Radioelektronika ta telekomunikatsii. 885, 154-167 (2017), (in Ukrainian).

[6] Melen M. V., Kozun V. I. Metod otsinky efektyvnosti kompleksnoi systemy kontroliu pravylnosti funktsionuvannia telekomunikatsiinykh system bezdrotovoho zviazku. Tezy dopovidei IX Mizhnarodnoi naukovopraktychnoi konferentsii "Suchasni problemy i dosiahnennia v haluzi radiotekhniky, telekomunikatsii ta informatsiinykh tekhnolohii" (03-05 October 2018, Zaporizhzhia), p. 49-50, (in Ukrainian).

[7] Iyudu K. A. Nadjozhnost', kontrol' i diagnostika vychislitel'nyh mashin i sistem. Moskva, Vysshaja shkola (1989), (in Russian).

[8] Matov V. I., Belousov Yu. A., Fedoseev E. P. Bortovye cifrovye vychislitel'nye mashiny i sistemy. Moskva, Vysshaja shkola (1988), (in Russian).

[9] Korolyuk V.S. Ukrupnenie slozhnyh sistem. (Metod. aspekty). Kibernetika. 1, 129-132 (1977), (in Russian). 
[10] Korolyuk V.S., Turbin A.F. Fazovoe ukrupnenie slozhnyh sistem. Kyiv, Vyshha shkola (1978), (in Russian).

[11] Korolyuk V.S., Turbin A. F. Processy markovskogo vosstanovlenija v zadachah nadjozhnosti sistem. Kyiv, Naukova dumka (1982), (in Russian).

[12] Egunov V.P., Shuvalov M. M. Rezervirovanie i vosstanovlenie v telekommunikacionnyh setyah. Vestnik SibGUTI. 2, 3-10 (2012), (in Russian).

[13] Komarova L. O., Shmatko V.S. Optymalne rezervuvannia komutatsiinykh vuzliv telekomunikatsiinoi merezhi. Telekomunikatsiini ta informatsiini tekhnolohii. 1, 49-53 (2015), (in Ukrainian).

[14] Barzilovich E. Yu., Beljaev Yu. K., Kashtanov V. A., Kovalenko I. N., Solov'ev A. D., Ushakov I. A. Voprosy matematicheskoj teorii nadezhnosti. Moskva, Radio i svjaz' (1983), (in Russian).

[15] Nadezhnost' v tehnike. Modeli otkazov. Osnovnye polozhenija: GOST 27.005-97. 45 p. (Mezhgosudarstvennyj standart), (in Russian).

[16] Artamonov G. T., Brehov O. M. Analiticheskie verojatnostnye modeli funkcionirovaniya. Moskva, Energiya (1978), (in Russian).

[17] BeicheltF., Franken P. Zuverlässigkeit und Instandhaltung: mathematische Methoden. Berlin, Verlag Technik (1984), (in German).

\title{
Напівмарковська надійнісна модель функціонування телекомунікаційної системи безпроводового зв'язку із комплексною системою контролю
}

Бобало Ю. Я., Горбатий І. В., Кіселичник М. Д., Мединський І. П., Мелень М. В.

\author{
Національний університет "Львівська політехніка",
} вул. С. Бандери, 12, Лъвів, 79013, Україна

\begin{abstract}
Для високонадійної телекомунікаційної системи з комплексною системою контролю побудовано математичну надійнісну модель у вигляді напівмарковського процесу відмов і відновлень, знайдено основні характеристики цього процесу й отримано аналітичний вираз, за допомогою якого можна оцінити імовірність перебування системи в працездатному стані. Цей вираз залежить від параметрів напівмарковського процесу, які визначаються через надійнісні характеристики контрольованих модулів, ï апаратних засобів контролю і параметри застосованих засобів контролю правильності функціонування розглядуваної системи.
\end{abstract}

Ключові слова: високонадійна система, комплексна система контролю, напівмарковський проц,е, рівняння марковсъкого відновлення, система безпроводового зв'язку.

2000 MSC: $60 \mathrm{~J} 20,60 \mathrm{~K} 15,60 \mathrm{~K} 20$

УДК: 621.39 